Proceedings

\title{
Influence of Tourist Behavior Mapping in the Development of Pilgrim Cities
}

1 PhD Candidate, Dept. of Architecture and Planning, MNIT Jaipur

2 Urban planner

3 Associate Professor, Dept. of Architecture and Planning, MNIT Jaipur

4 Assistant Professor, Dept. of Architecture and Planning, MNIT Jaipur

* Correspondence: 2019rar9007@mnit.ac.in; Tel: +91-9685351531

\begin{abstract}
Given the evolving nature of the existing communities and the incoming tourists, the study of tourist behavior incorporating cultural attitudes, community perceptions, and multiple characteristics of its stakeholders has become a key element in the overall analysis of tourism's impact and sustainable development of historic cities. This study attempts to explore the behavioral characteristics of tourists to analyze their influence on the holistic development of pilgrim cities. The research, undertaken in two pilgrim cities - Puri, Odisha, and Pushkar, Rajasthan, highlighted the demand for multidisciplinary decision-making in the comprehensive development of touristoriented cities.
\end{abstract}

Keywords: Tourist Behavior, Cultural Mapping, Tourism, Urban Planning, Pilgrim Cities

\section{Introduction}

In this era of rapid globalization, the multi-faceted contributions of tourism in shaping the growth and character of urban regions are known by all. Whether economic, environmental, social, or spatial transformations, tourism impacts global development in both tangible and intangible aspects. As per the Economic Impact Report by the World Travel and Tourism Council, the Travel \& Tourism sector grew by 3.5\% percent in 2019, outpacing the global economic growth of $2.5 \%$ with a contribution of 8.9 trillion USD to the world's GDP. The tourism sector provided 330 million jobs globally, which makes up for around one in ten jobs around the world pertaining to this. [1] The study of tourist behavior has become an essential element in the overall analysis of tourism's impact on a region's development. Although there is ample research available on studying tourists' behaviors and their impact on the tourism industry, the role of studying area-specific tourists' behavioral characteristics remains highly neglected in tourism development strategies. Recent studies highlight that the direct contribution of tourism is nearly 194 billion USD and around $6.8 \%$ of the GDP in India. In a country like India, where the cultural and regional characteristics change every few kilometers, it is evident that the tourist behavioral characteristics are bound to vary with regions too. Cultural mapping has developed in response to the need to understand this notion of local distinctiveness. Local communities have their voice heard through their involvement in the mapping process. [2]

Considering the social role of the tourist, the behavior of tourists sets the norms not just to be followed by people yet to engage in travel but as well as serves as an indicator of the behavior of others who do and sets as a stepping ground to predict future tourist behavior. Research related to Tourist behavior has always been in the context of consumer behavior in the purchase, uptake and abandonment of tourist services predominantly in 
the hospitality sector. However, the demand of multidisciplinary decision-making in the comprehensive development of characteristically tourist-oriented cities requires an understanding and application of the influence of tourist behavior in future planning of the cities. Through exhaustive literature review and initial survey, from nine identified concepts in Tourist behavior, five concepts, namely Values, Motivation, Expectations, perception and satisfaction were determined to be taken up in the execution of the research. [3][4] Travel values and motivations that psychologically dictate the person to behave in a certain way are considered one of the most important influences of tourist behavior. [5][6][7] A tourist experience based on exposure to the area which can be formed through word of mouth and advertising sources, or based on personal and individual characteristics or motivation when reaches or exceeds their expectations will create a positive memory to be recreated by them or passed on further. [8][9]

A pilgrim city may vary in size, demographics, socio-ethnic characteristics, and local communities and tourists/pilgrims. Uni-dimensional plans often tend to neglect the role of the tourist and local communities' attitudes towards various tourism development strategies. This study explores the behavioral characteristics of tourists inherent to the cities' character to analyze their influence on the holistic development of pilgrim cities.

\section{Area of Study}

1 2 3 4 5

The research was undertaken in two pilgrim cities Puri, Odisha and Pushkar, Rajasthan. Being part of the most revered places to visit in India, they have their unique religious or spiritual characteristics and are part of the leisure and recreational experiences of the tourists. The emphasis on these two pilgrim cities was due to their proximity to prominent tourist destinations in India's eastern and western regions.

Puri, the abode of Lord Jagannath, is one of the four celebrated religious centers of Hindus, situated on the shores of Bay of Bengal situated $60 \mathrm{kms}$ from Bhubaneswar, capital of Odisha, forming a golden triangle in the State's domestic tourist circuit. It is also well connected with the significant tourism circuits of its neighboring states like West Bengal, Andhra Pradesh and Chhattisgarh. Apart from the revered char dhams of India i.e., Puri, Badrinath, Dwarka, and Rameswaram, Pushkar is referred to as the fifth dham for its mythological significance. Pushkar, being one of the prominent pilgrim cities due to its heritage and locational settings as it has the only Brahma temple in the world. History illustrates the Pushkar Lake as bounded by 52 palaces and 500 temples. Pushkar is situated close to Jaipur and Agra, two of India's most reputed tourist destinations. [10] Development pressures that Puri and Pushkar face are tremendous as the worship place of Lord Jagganath and Lord Brahma. They are under continuous pressure for commercial, residential and recreational development. Despite being well-known tourist destinations and various government schemes to their name, they lack the basic facilities, which creates a substantial negative impact on the presence of various heritage precincts and temples in the vicinity, which is being encroached due to infrastructure stress. Due to its heavy cyclone-prone coastline, Puri is also located in a high disaster risk zone. Pushkar Lake is under constant threat due to increasing encroachment and over-dependence due to unregulated pilgrim activities.

\section{Research Methodology}

The paper advocates inclusion and participation of the communities in the identified cities to address the characteristics of tourists and keeps identified communities at the forefront to illustrate their perception and unique indigenous values, among others. The research was based on the five identified parameters, namely Values, Motivation, Expectations, perception and satisfaction, to analyze the tourist behavior in these two cities. 
Primary Data was collected through a mix of qualitative and quantitative methods consisting of surveys, Interviews, PhotoVoice, and Narrative inquiry with focus group discussions, including the community at every stage of the research. Separate questionnaires were developed to collect data on the behavioral characteristics of the tourist and the local communities. This data from tourists was collected for both incoming tourists for their expectations and outgoing tourists to study their change in attitude, experience and satisfaction. PhotoVoice surveys were performed to identify the region-specific characteristics of various cultural associations and how the local community perceived tourism development and tourist behavior.

\section{Data Collection and Results}

The research was conducted in phases keeping in mind the varying amounts of tourist footfall in the two cities depending on the festivals and events of religious and cultural importance. It was observed that the socio-cultural heritage value of religious areas attracted the most number of tourists in both cities. Tourists' profile was also questioned to understand the trip's purpose and the motivation toward the city. It was identified that tourists were interested in recreational activities and pilgrimage in Pushkar. However, through a varied tourist age cohort, while in Puri, the tourists were more focused on the temple and its allied activities than its beach. The city's sprawling beaches are used more for relaxation than the main tourist motivation. Figure 1 (a) illustrates the pattern of tourist flow in Puri during the peak and regular seasons, showing the visitation trend structure. It is toward the town's beachside during the peak season, while round the year, it is towards the temple core zone consisting of various temples and mathas. While for Pushkar, Figure 1 (b) depicts the tourist flow throughout the city perennially due to its accessible routes and compactness.
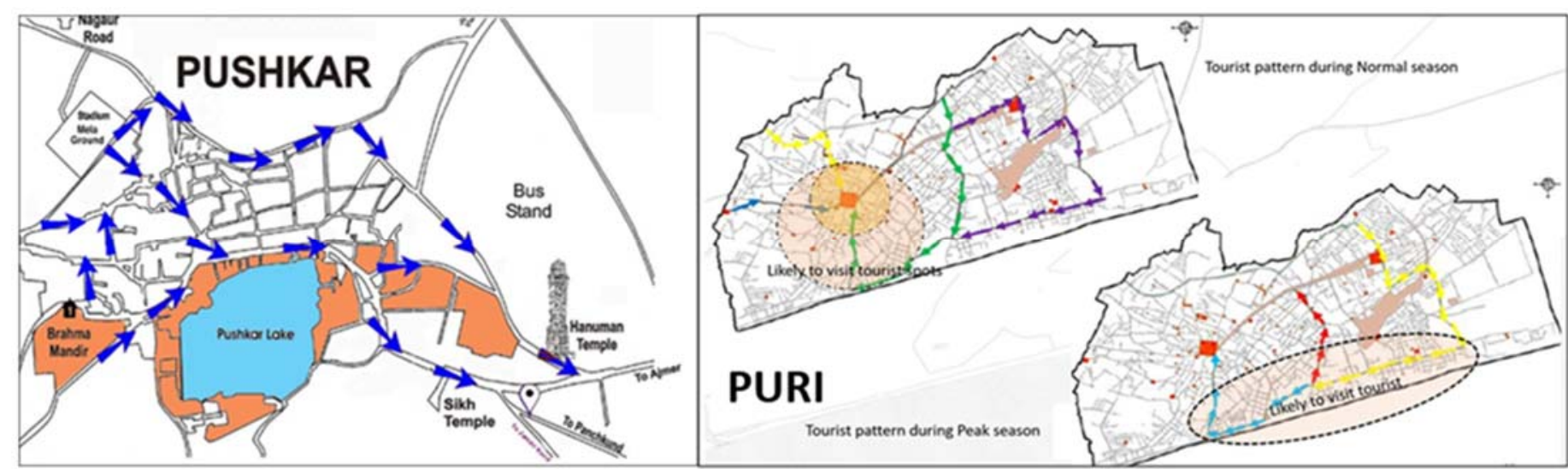

Figure 1. Tourists pattern mapping through stakeholders (a) tourists flow in Pushkar (b) tourist pattern in different seasons of Puri.

A heritage infrastructure survey was conducted to get an idea of the facilities provided and maintained for the tourists. Subsequently, primary surveys were conducted among the tourists to analyze their awareness about the facilities mentioned above. It was observed that tourists were more satisfied with the accessibility, attitude of the locals and travel facilities available at their behest. In contrast, basic tourist information, healthcare facilities and recreational arrangements required more attention on the tourism planning and development. It was also seen that the lack of awareness amongst tourists about the existing facilities contributed towards their dissatisfaction and negative perception of the cities. These data on multiple variables were thoroughly analyzed based on identified parameters to conclude that tourist behavioral mapping can significantly impact the development of pilgrim cities. This impact was found to affect regional development and contribute positively to the overall image of the two cities. It was concluded that mapping 
cultural and behavioral characteristics could be utilized as an effective tool for planning 1 historic cities to deal with future changes in their character.

\section{Conclusion}

Historically, the approach to tourism planning in India can be seen as a consumer-industry-centric one where the facilities, service industry, and tourist attractions play a vital role in the development strategies. However, as the nature of the existing communities and the incoming tourists evolves, such a uni-dimensional approach needs to evolve and incorporate multiple criteria of behavioral characteristics of the involved stakeholders. Especially in the case of historic cities and religious tourism, the need to incorporate cultural attitudes, community perceptions and how the psychology of the tourist is impacted by it has become the need of the hour. Understanding the need for culture mapping also brings along the need to understand all the involved stakeholders. While the comfort, safety and satisfaction of the incoming tourists are essential parameters in tourism planning, the role of shaping positive local community attitudes and their inclusive participation in the development process need to be incorporated while analyzing tourist behaviors.

Funding: This research received no external funding.

\section{References}

1. Decrop, A. (2006), Vacation Decision-Making, Wallingford, CABI-Publishing.

2. George, R. (2004), Marketing South African Tourism and Hospitality, 2nd ed, Oxford, Oxford University Press.

3. Juvan, E. and Omerzel, D. G. (2017) 'Tourist Behaviour : An Overview of Models to Date', Management International Conference, pp. 23-33.

4. March, R. G., \& Woodside, A. G. (2005), Tourism Behavior: Travelers' Decisions and Actions, CABI Publishing,Cambridge

5. Scott A. Cohen, Girish Prayag \& Miguel Moital (2014) Consumer behaviour in tourism: Concepts,influences and opportunities, Current Issues in Tourism, 17:10, 872-909

6. Sheng, C.W., \& Chen, M. C. (2012). A study of experience expectations of museum visitors. Tourism Management, $33,53-60$.

7. Taylor, Ken. (2013). Cultural Mapping: Intangible Values and Engaging with Communities with Some Reference to Asia. The Historic Environment: Policy \& Practice. 4. 50-61. 10.1179/1756750513Z.00000000024.

8. World Travel and Tourism Council. (2020, June). Global Economic Impacts and Trends 2020. Accessed December 01, 2021.

9. Zeithaml, V. A., Berry, L. L., \& Parasuraman, A. (1993). The nature and determinants of customer expectations of service. Journal of Academy of Marketing Science, 21(1), 1-12.

10. India tourism statistics, 2019. Tourism.gov.in. https://tourism.gov.in/sites/default/files/2020-04/India\%20Tourism\%20Statistics\%202019.pdf. Published 2020. Accessed December 01, 2021. 